\title{
Using the Job Characteristics Model to Measure the Motivating Potential of Flightdeck Positions
}

\author{
Anthony L. Patti \\ University of New Orleans \\ and \\ Triant G. Flouris \\ Auburn University
}

\begin{abstract}
This paper explores the potential of using the Job Characteristics Model (JCM) for analyzing flightdeck positions. The JCM has been successfully used to study a variety of job designs and the effects prescribed treatments have on the job designs. This paper presents an overview of the job characteristics model, discusses the model's critical psychological states and shows how the Job Diagnostic Survey (JDS) can be used to measure the motivating potential of flightdeck positions. The results from our analysis and the model itself will be useful in the design of individualized LOFT (Line Oriented Flight Training) and CRM (Crew Resource Management) LOFT programs. Additionally, the JCM can be used to study the effects of automation, operation type (passenger vs. cargo), tenure as a pilot, and tenure in type on pilot motivation. From a longitudinal perspective, current data collection can serve as baseline measures for studying the aggregate, long-term effects of flightdeck job design changes.
\end{abstract}

\section{INTRODUCTION}

The purpose of this project is to explore the potential of using the Job Characteristics Model (JCM) for analyzing flightdeck positions. The JCM has been successfully used to study a variety of job designs and the effects prescribed treatments have on the job designs (Cheser, 1998; Dodd \& Ganster, 1996; Fok et al., 1999; Fok et al., forthcoming; Shafer et al., 1995). This paper presents an overview of the job characteristics model, discusses the model's critical psychological states, and shows how the Job Diagnostic Survey (JDS) can be used to measure the motivating potential of flightdeck positions.

Our research at this stage is an attempt to adapt the JCM and to verify it, empirically, in the flightdeck setting. We are planning to achieve this through the use of statistical analysis of data being collected from representative carriers in the United States. The next stage of this research will focus on verifying the JCM using an international sample. Once the JCM has been verified in the flightdeck setting, there are many potential uses for it, both by airlines and researchers of airline operations. The results from our analysis and the JCM itself will be useful in the design of individualized LOFT and CRM LOFT programs. Additionally, the JCM can be used to study the effects of automation, operation type (passenger vs. cargo), tenure as a pilot, and tenure in type on pilot motivation. From a longitudinal perspective, current data collection can serve 
as baseline measures for studying the aggregate, long-term effects of flightdeck job design changes.

\section{OVERVIEW OF THE JOB CHARAC- TERISTICS MODEL}

Hackman and Oldham's (1980) Job Characteristics Model (JCM) describes the link between a job's core characteristics, critical psychological states, and outcomes (see Figure 1). Basically, whenever certain core job characteristics are present, they lead to the critical psychological states of experienced meaningfulness of the work, experienced responsibility for the outcomes of the work, and knowledge of the actual results of the work activities. The degrees to which all three of these states are present contribute to the motivating potential score (MPS) of a job. Higher MPS is related to higher outcomes. These outcomes include high internal work motivation, high growth satisfaction, high general job satisfaction, and high work effectiveness.

The proposed relationships in the JCM are moderated by individual differences. For instance, an individual's knowledge and skill will affect the model's relationships. High knowledge and skill suggests an individual will perform well. However, low MPS jobs have low internal motivating potential. Thus, how well a person performs in a low MPS job will not affect their feelings about his or her work. However, in a high MPS job, good performance will lead to positive feelings and poor performance will lead to negative feelings. Thus in high MPS jobs, a person's knowledge and skill will affect the degree to which they experience positive outcomes from doing their job.

Similarly, an individual's growthneed strength (GNS) and context satisfaction will moderate the model's proposed relationships. GNS is a measure of an individual's desire for higher personal accomplishments, learning, and improved social, economic, and professional status. High GNS individuals are motivated to grow while low GNS individuals may be satisfied when basic physiological and security needs are met.

Context satisfaction refers to an individual's satisfaction with the work context. For instance, individuals who feel they are significantly underpaid or who do not feel well liked and/or respected at work will have low context satisfaction. With individuals that are low on GNS and low on context satisfaction there is no relationship (or a small negative relationship) between MPS and outcomes. When both GNS and context satisfaction are high, there is a strong positive relationship between MPS and outcomes. When only one or the other of GNS and context satisfaction are high, there is a moderate positive relationship between MPS and outcomes (Hackman \& Oldham, 1980).

\section{CRITICAL PSYCHOLOGICAL STATES}

Five job characteristics have been shown to contribute to the three critical psychological states of meaningfulness, responsibility for outcomes, and knowledge of actual results of the work (Hackman \& Lawler, 1971; Hackman and Oldham, 1976; Turner \& Lawrence, 1965). Three of the job characteristics contribute to meaningfulness. One of the job characteristics contributes to responsibility for outcomes. Another of the job characteristics contributes to knowledge of actual results of the work. These five job characteristics are discussed below. To illustrate the usefulness of using the JCM for studying flightdeck positions, propositions regarding expected differences based on operations type (passenger or cargo), degree of flightdeck automation (conventional versus glass cockpit), overall flightdeck 
experience, and in-type flightdeck experience are stated. These flightdeck environment variables are not intended to be a comprehensive list of variables that can affect job satisfaction. These variables are only discussed as examples for the potential uses of the JCM in analyzing flightdeck positions.

\section{Experienced Meaningfulness}

The core job characteristics that contribute to the critical psychological state of meaningfulness are skill variety, task identity, and task significance (Hackman \& Oldham, 1980). These characteristics are described here.

Skill variety. Skill variety is defined as "the degree to which a job requires a variety of different activities in carrying out the work, involving the use of a number of different skills and talents of the person" (Hackman \& Oldham, 1980, pg. 78). It has been shown that performing work that requires a number of skills leads to feelings of meaningfulness in humans. It is not necessary for the work to be considered important or significant in the greater scheme of things. Rather, if the work requires an individual to stretch his or her talent, it will be considered meaningful to the individual. For instance, note the meaningfulness of excellence in sporting activities to the participants. Though being good at golf is not a significant contribution to the world at large, many individuals find meaningfulness in improving their game. Similarly, one does not have to be a commercial airline pilot to experience meaningfulness from piloting an aircraft.

A substantial amount of skill variety is required in flightdeck positions. Technical skills and significant knowledge are required to fly aircraft safely. Additionally, significant motor skills, communication skills, cognitive skills, and people skills are also required. Skill variety may be perceived as increasing as the flightdeck environment becomes more automated. Newer and more advanced avionics and aircraft monitoring and control systems present new challenges to pilots. Alternatively, automated flightdecks may be viewed as decreasing skill variety as they take over more of the flightdeck tasks. It will be interesting to note the change in perceived skill variety as flight experience in general and tenure in a particular flightdeck environment increase. As time goes on and the same tasks are performed day-in and day-out, perceived skill variety may decrease because the individual no longer feels challenged.

Task identity. Task identity is defined as "the degree to which a job requires completion of the whole and identifiable piece of work, that is, doing a job from beginning to end with a visible outcome" (Hackman \& Oldham, 1980, pg. 78). As might be expected, workers that perform only a small piece of a large job experience less meaningfulness than workers who perform larger portions of the job. It is more difficult for a worker to identify with the project/product and the benefits it provides to society when he or she only contributed a small portion of the overall task.

There is substantial task identity associated with flightdeck positions. If you define the task as transporting passengers and/or cargo from point $\mathrm{A}$ to point $\mathrm{B}$, flightdeck positions are involved from beginning to end. Task identity is expected to be consistent across types of flight operations (passenger or cargo). Additionally, it is unlikely that overall flightdeck experience, and in-type flightdeck experience will significantly affect task identity. However, flightdeck automation may impact task identity. Some individuals may believe that the computers are 
performing a bulk of the task. Therefore, they may perceive less direct connection to the task.

Task significance. Task significance is defined as "the degree to which the job has a substantial impact on the lives of other people, whether those people are in the immediate organization or in the world at large" (Hackman \& Oldham, 1980, p. 79). As stated above, an activity does not have to be significant in the greater scheme of things in order to produce feelings of meaningfulness. However, the degree to which others value the activity will contribute to feelings of meaningfulness.

Task significance will likely vary depending on the type of flight operations. Flightdeck positions on large passenger jets will likely be considered highly significant, simply because they affect the lives and safety of a large number of people. While transporting cargo is important and affects a large number of people, human lives are not at significant risk (except for the pilot and crew, of course). Thus, it is likely that cargo pilots will view their positions as less significant than passenger carrying pilots. Likewise, there is likely a positive correlation between perceived task significance and aircraft size as determined by the number of seats. Additionally, we may find that the type of cargo (hazardous vs. non-hazardous, medical vs. non-medical) being carried affects perceptions of task significance. It is unlikely that flightdeck automation, overall flightdeck experience, and in-type flightdeck experience will significantly affect task significance.

Skill variety, task identity, and task significance all contribute to the meaningfulness experienced by the flightdeck professional. However, for a job to have motivating potential, individuals must feel responsible for the outcomes of a task and have knowledge of the outcomes of the task. A job characteristic called "autonomy" affects the responsibility for the outcomes an individual feels and "feedback" affects the knowledge of the actual outcomes.

\section{Autonomy}

Autonomy is defined as "the degree to which the job provides substantial freedom, independence, and discretion to the individual in scheduling the work and in determining the procedures to be used in carrying it out" (Hackman \& Oldham, 1980, p. 79). Jobs with high autonomy afford workers the chance to claim the outcomes, good or bad, as a result of their efforts. Workers who merely follow stringent procedures may view a substantial portion of the outcome as a result of the procedure rather than their efforts.

In the interest of safety, much of the autonomy of flightdeck positions has been removed. While FAA regulations allow pilots to deviate from the regulations in times of emergency, the vast majority of flightdeck work is carried out via established checklists and procedures. Any deviation from these procedures often requires substantial justification. Thus, it is expected that flightdeck positions as a whole will score relatively low on autonomy.

The perceived autonomy of passenger carrying pilots may be lower than for cargo carrying pilots. Scheduled passenger carrying and cargo carrying operations in the United States are subject to the same regulations (FAA Part 121). These regulations include the requirements for the issuance and maintenance of airline operating and fitness certificates. However, passenger operators set stricter company regulations in their Flight Operations Manuals, many of which deal with issues such as passenger handling that are not issues for cargo operators. Thus, pilots flying for passenger operations are subject to 
increased rules and scrutiny. Additionally, cargo only operations are primarily conducted during the night. Due to the reduced amount of traffic at night, airspace management requirements are not as strict as for day operators (primarily passenger operators). Thus, cargo only pilots have more freedom in picking the routes they fly. This may also contribute to cargo only pilots perceiving a higher degree of autonomy.

The degree of flightdeck automation will likely affect a pilot's perceived autonomy. The more automated the flightdeck becomes, the more tasks that are assumed by the aircraft systems. Thus, pilots may see automated systems as "taking over" their jobs. The perception of autonomy may come down to who has the last word, the pilot or the computer. Boeing designs give the pilot the last word on aircraft operations. That is, the pilot can override the flightdeck automation if he or she deems it necessary. However, Airbus designs give the aircraft systems the final word. If the aircraft computers believe inputs from the pilot(s) would place the aircraft in an unsafe situation, the pilot(s)' commands are overridden. Thus, it will be interesting to see if Boeing pilots report higher levels of autonomy than Airbus pilots.

\section{$\underline{\text { Job Feedback }}$}

Job feedback is defined as "the degree to which carrying out the work activities required by the job provides the individual with direct and clear information about the effectiveness of his or her performance" (Hackman \& Oldham, 1980, p. 80 ). To be internally motivating, a job must provide the worker with knowledge of the outcomes of his or her efforts. Note that the focus here is on feedback from the job itself. Feedback from other people such as managers and/or supervisors does impact the knowledge of outcomes. However, the MPS is a measure of the motivating potential of a job's design.

The perception of feedback in flightdeck positions will likely be high. The squeak of the tires on the runway at the intended destination provides immediate and unequivocal evidence of performance success. Likewise, the outcomes of simulator training exercises are quite apparent.

Feedback is not expected to vary with operations type, flightdeck automation, overall flightdeck experience, or in-type flightdeck experience. In all these cases, the feedback from the job itself is unaffected.

\section{THE JOB DIAGNOSTIC SURVEY}

Hackman and Oldham (1975 \& 1980) created the Job Diagnostic Survey (JDS) to measure the variables and constructs in the JCM. The survey instrument is administered to individual workers and elicits their perceptions of the attributes of their jobs. Responses are recorded on seven point Likert scales.

Sections one and two of the survey ask respondents questions about their current job. The answers to these questions are selectively combined to form measures of the five job characteristics. For example, skill variety is obtained by averaging the score on the following three questions from Sections one and two:

Section One, \#4: How much variety is there in your job? That is, to what extent does the job require you to do many different things at work, using a variety of your skills and talents?

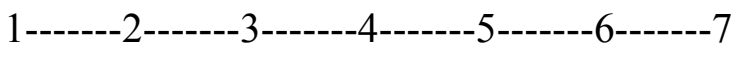

Very little, the job requires Moderate variety. Very much; the job requires me to do many different things over 
and over again. Things using a number of different skills and talents.

Section Two, \#1: How accurate is the following statement in describing your job? The job requires me to use a number of complex, high level skills. $(1=$ very inaccurate $-7=$ very accurate)

Section Two, \#5: How accurate is the following statement in describing your job? The job is quite simple and repetitive. $(1=$ very inaccurate -7 = very accurate; note that this item is reverse scored to help reduce bias)

Sections three and five are used to measure the experienced psychological states. Section three asks respondents questions about how they personally feel about their job. Section five asks respondents to indicate how other people in the organization that hold the same job feel about their job. Both sections are used to gain an overall measure of the experienced psychological states rather than from a single perspective. For example, experienced meaningfulness is measured by four questions. They are:

Section Three: How much do you agree with each statement? ( 1 = disagree strongly -7 = agree strongly) \#4: Most of the things I have to do on this job seem useless or trivial. (reverse scored) \#7: The work I do in this job is very meaningful to me.

Section Five: How much do you agree with each statement? $(1=$ disagree strongly $-7=$ agree strongly)

\#3: Most people on this job feel that the work is useless or trivial. (reverse scored) \#6: Most people on this job find the work very meaningful.
Sections three and five also contain questions that assess the affective outcomes such as general job satisfaction and internal work motivation.

Section four asks questions about job satisfaction. Some questions are used to assess one of the affective outcomes called growth satisfaction. Other questions obtain measures of context satisfaction such as satisfaction with job security, compensation, co-workers, and supervision.

Sections six and seven measure growth need strength. Section six asks "would like" type questions. Respondents are asked the degree to which they would like to have certain characteristics (respect and fair treatment from their supervisor, job security, friendly co-workers, quick promotions, etc.) present in their jobs. The questions in section seven ask respondents to choose between two types of jobs. The choices respondents make indicate what is more important to them and measures their growth need strength. For example, respondents are forced to choose (on a seven point Likert scale) between "a job with a supervisor who respects you and treats you fairly" and "a job that provides constant opportunities for you to learn new and interesting things." A person that has high GNS would be less worried about being treated fairly and more interested in a job that provides constant opportunities to learn new and interesting things. Another question asks respondents to choose between "a job where there is a real chance of you could be laid off" and "a job with very little chance to do challenging work." A person with high GNS would not be as concerned with job security as much as they would want to avoid a job that is not challenging.

The JDS has been used in a variety of organizations and subjected to many empirical tests (e.g., Renn \& Vandenberg, 1995; Fried \& Ferris, 1987; Hogan \& 
Martell, 1987; Cathcart, Goddard, \& Youngblood, 1978; Dunham 1976, Dunham, Aldag, \& Brief, 1977; Pierce \& Dunham, 1978; Stone \& Porter, 1977). Our research is an attempt to use the model in the airline industry and to verify it using the same strict empirical testing as has been used to verify it in other industries.

We believe the JCM will fit the flightdeck environment well. The primary uses for the JCM are in jobs that employ high GNS individuals. It is in these settings that the JCM's correlations are strongest. We suspect that individuals who aspire to flightdeck positions have high GNS (our survey will test this). Additionally, the JDS is not job specific and can be used to analyze a variety of jobs. Thus, very few changes to the JDS are needed.

\section{SUMMARY AND FUTURE RESEARCH}

We believe using the JCM to study flightdeck positions has considerable potential. The first step is to validate its appropriateness in the flightdeck environment. Data are currently being gathered to do just that. Once this is accomplished, the effects of different variables such as degree of flightdeck automation, operation type, tenure as a pilot, and tenure in type on job satisfaction can be tested. As this research stream progresses, researchers and practitioners will undoubtedly identify other variables and constructs that affect job satisfaction in the flightdeck environment. The results of this research will provide a vehicle for testing their theories.

Also important is that this research will provide a benchmark measure of job satisfaction in the flightdeck environment. It will be interesting and instructive to repeat this research annually so that trends in job satisfaction can be monitored. The JDS provides measures of job satisfaction and, perhaps more important, measures of the underlying constructs that affect job satisfaction. The analysis of trends in these latent variables will be necessary in understanding why changes in job satisfaction are occurring. This research stream should prove interesting to both practitioners and researchers. 
Figure 1.

JOB CHARACTERISTICS MODEL

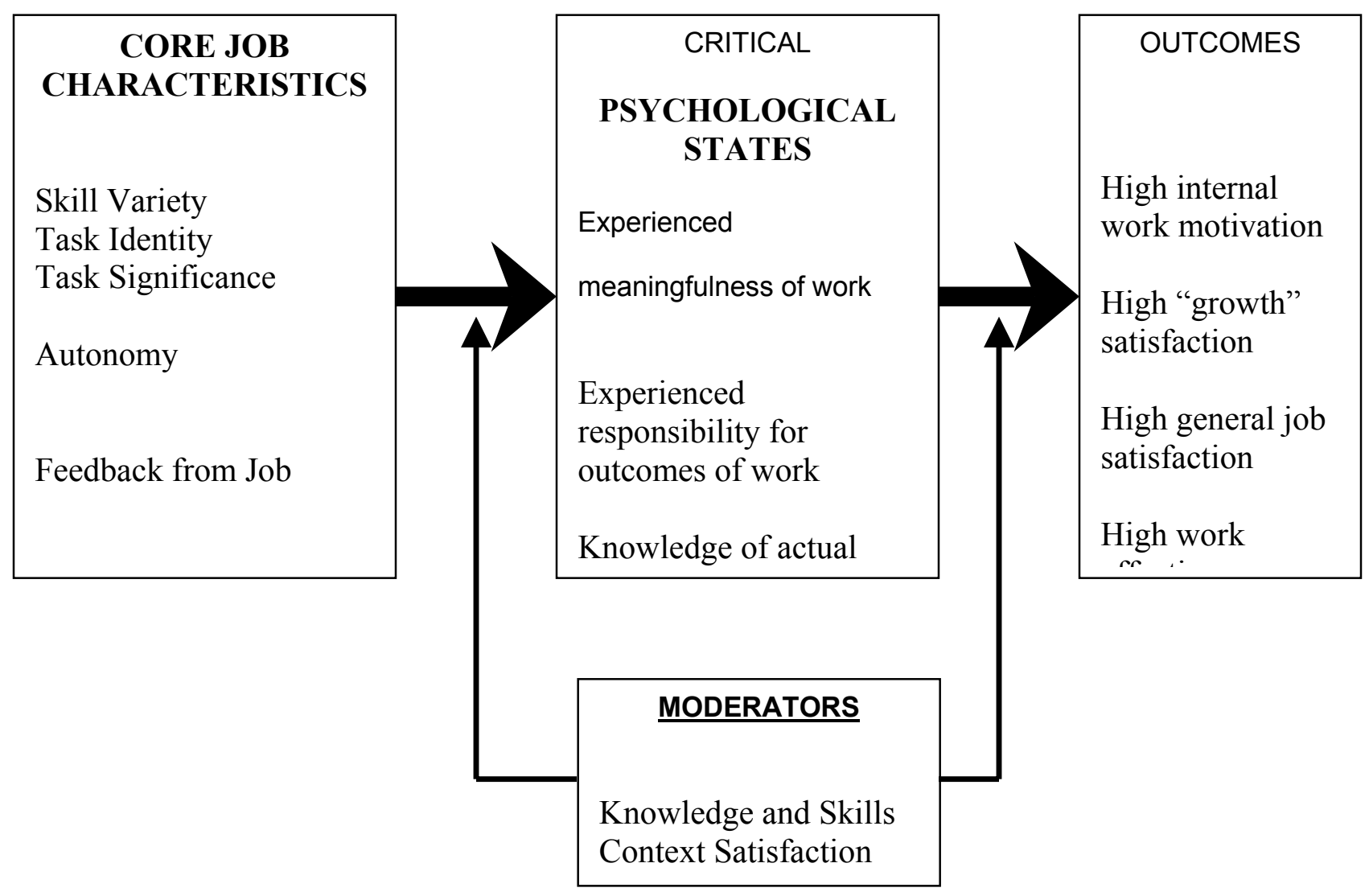




\section{REFERENCES}

Cathcart, J. S., Goddard, R. G. and Youngblood, S. A. (1978). "Perceived Job Design Constructs: Reliability and Validity. Technical Report No. 7, Center for Management and Organizational Research, University of South Carolina.

Cheser, R. N. (Jul, 1998). "The Effect of Japanese Kaizen on Employee Motivation in U.S. Manufacturing.” International Journal of Organizational Analysis. 6(3), 197-217.

Dodd, N. G. and Ganster, D. C. (Jul, 1996). "The Interactive Effects of Variety, Autonomy, and Feedback on Attitudes and Performance." Journal of Organizational Behavior, 17(4), 329-347.

Dunham, R. B. (1976). "The Measurement and Dimensionality of Job Characteristics." Journal of Applied Psychology, 61, 404-409.

Dunham, R. B., Aldag, R. J. and Brief, A. P. (1977). "Dimensionality of Task Design as Measured by the Job Diagnostic Survey." Academy of Management Journal, 20, 20-223.

Fok, L. Y., Hartman, S. J., Patti, A. L., \& Razek, J. R. (1999). "Human Factors Affecting the Acceptance of Total Quality Management" International Journal of Quality and Reliability Management. 17(7), 714-729.

Fok, L. Y., Hartman, S. J., Patti, A. L., \& Razek, J. R. (forthcoming). "The Relationship Between Equity Sensitivity, Growth Need Strength, Organizational Citizenship Behavior, and Reactions to the Quality Environment: A Study of Accounting Professionals." forthcoming in the Journal of Social Behavior and Personality.

Fried, Y. and Ferris, G. R. (1987). "The Validity of the Job Characteristics Model: A Review and Meta-Analysis." Personnel Psychology, 40(2), 287-322.

Hogan, E. A. and Martell, D. A. (1987). "A Confirmatory Structural Equations Analysis of the Job Characteristics Model." Organizational Behavior and Human Decision Processes, $39(2), 242-263$.

Hackman, J. R. and Lawler III, E. E. (1971). "Employee Reactions to Job Characteristics." Journal of Applied Psychology Monograph. 55, 259-286.

Hackman, J. R. and Oldham, G. R. (1975). "Development of the Job Diagnostic Survey." Journal of Applied Psychology, 60, pp. 159-170.

Hackman, J. R. and Oldham, G. R. (1976). "Motivation Through the Design of Work: Test of a Theory." Organizational Behavior and Human Performance, 16, 250-279.

Hackman, J. R. and Oldham, G. R. (1980). Work redesign. Addison-Wesley, Reading, Mass.

Pierce, J. L. and Dunham, R. B. (1978). "The Measurement of Perceived Job Characteristics: The Job Diagnostic Survey Versus the Job Characteristics Inventory." Academy of Management Journal, 21, 123-128.

Renn, R. W. and Vandenberg, R. J. (1995). "The Critical Psychological States: An Underrepresented Component in Job Characteristics Model Research." Journal of Management, 21(2), 279-303.

Shafer, S. M., Tepper, B. J., Meredith, J. R., and Marsh, R. (Feb, 1995). "Comparing the Effects of Cellular and Functional Manufacturing on Employees' Perceptions and Attitudes." Journal of Operations Management, 12(2), 63-74. 
Stone, E. F. and Porter, L. W. (1977). "On the Use of Incumbent-supplied Job Characteristics Data." Paper No. 635, Institute for Research in the Behavioral, Economic, and Management Sciences, Purdue University.

Turner, A. N. and Lawrence, P. R. (1965). Industrial Jobs and the Worker. Harvard Graduate School of Business Administration, Boston, Mass. 